\title{
Part of nature and division in Margaret Cavendish's materialism
}

\author{
Jonathan L. Shaheen ${ }^{1}$
}

Received: 1 February 2016 / Accepted: 27 January 2017 / Published online: 23 June 2017

C The Author(s) 2017. This article is an open access publication

\begin{abstract}
This paper pursues a question about the spatial relations between the three types of matter posited in Margaret Cavendish's metaphysics. It examines the doctrine of complete blending and a distinctive argument against atomism, looking for grounds on which Cavendish can reject the existence of spatial regions composed of only one or two types of matter. It establishes, through that examination, that Cavendish operates with a causal conception of parts of nature and a dynamic notion of division. While the possibility of unmixed spatial regions is found to be consistent with both the doctrine of complete blending and Cavendish's anti-atomism by themselves, it is finally ruled out by a consideration of her theory of place. In fact, the geometrical question of the spatial relations between types of matter that drives the paper is ultimately exposed as illicitly mathematical from the perspective of Cavendish's metaphysics.
\end{abstract}

Keywords Margaret Cavendish · Early modern metaphysics · Anti-atomism · Divisibility - Seventeenth century anti-mathematicism - Early modern female philosophers · New narratives in the history of philosophy · Individuation of bodies

Margaret Cavendish's materialism presents a number of interpretive challenges to historians of philosophy seeking to understand her metaphysics. The pressing interpretive question that I want to explore here concerns how to understand a basic tenet of Cavendish's materialism, which is usually called her doctrine of complete blending, following O'Neill (2001). As I explain in Sect. 1, Cavendish claims that nature is composed of three different types of matter: rational animate matter, sensitive animate matter, and inanimate matter. The "commixture" of these types is held to be so thorough that "no particle in nature can be conceived or imagined" that fails to contain

Jonathan L. Shaheen

1 Department of Philosophy, Uppsala University, Postal Box 627, 75126 Uppsala, Sweden 
all three of them $\left(O E P\right.$, p. 158) ${ }^{1}$ This is the doctrine of complete blending: the claim that (even) the smallest (conceivable or imaginable) parts or particles of nature are composites of all three kinds of matter.

O'Neill (2001)'s influential account of this doctrine interprets it to rule out the existence of unmixed spatial regions, that is, spatial regions containing or composed of only one or two types of matter. But O'Neill's interpretation presupposes that the notion of a particle in nature is geometrical, in the sense that the matter contained in an arbitrary spatial region always constitutes a (conceivable or imaginable) particle in nature. On my view, Cavendish has a non-geometrical theory of particles in nature, or as I shall regularly call them 'parts of nature', that renders the doctrine of complete blending, considered in relative isolation, consistent with the existence of unmixed spatial regions. I describe that non-geometrical theory, according to which parts of nature are the effects of motions, in Sect. 2.

But Cavendish has also been understood as adopting a popular argument against atomism in virtue of which the doctrine of complete blending might still turn out to be inconsistent with the existence of unmixed spatial regions. ${ }^{2}$ According to that popular argument, anything extended has parts, and is therefore at least conceptually divisible into those parts. If Cavendish's opposition to atomism is indeed derived from such an argument, then we would expect her to be committed to saying that any unmixed spatial region could, at least conceptually, be divided into an unmixed part of nature. The conceptual possibility of such a division might then be combined with the doctrine of complete blending to rule out the existence of unmixed spatial regions. ${ }^{3}$ I will show in Sect. 3 that Cavendish does not understand divisibility in the purely geometrical way at issue in this line of thought. The same goes for what she means by 'infinite

${ }^{1}$ I use the following abbreviations to refer to works published by Cavendish:

PF: Poems and Fancies (1653)

PPO: Philosophical and Physical Opinions (1655; second edition 1663)

PL: Philosophical Letters (1664)

OEP: Observations upon Experimental Philosophy (1666; second edition 1668)

TBW: The Description of a New World, Called The Blazing World (1666; second edition 1668)

GNP: Grounds of Natural Philosophy (1668)

CLP: A Collection of Letters and Poems: Written by several Persons of Honour and Learning, Upon divers Important Subjects, to the Late Duke and Dutchess of New Castle (1678)

For OEP, I use Cavendish (2001), except when citing the first edition of 1666 explicitly. For TBW, I use Cavendish (2003). Spelling in quotations is modernized without notice.

2 The two main anti-atomistic passages in Cavendish are "A Condemning Treatise of Atoms" in the prefatory material to $P P O$ and $O E P$, I.31, pp. 125-131. See Detlefsen (2006), Sect. 2 and Marshall (2014), Sect. 2a for the interpretation of Cavendish as adopting the popular argument. But cf. Kargon (1966), pp. 73-76, who holds that Cavendish is an atomist on the basis of her early atomist text $P F$; Clucas (1994), who holds that Cavendish rejects only a particular kind of atomism; and Stevenson (1996), who holds that Cavendish must remain an atomist despite herself due to other, allegedly more deeply held commitments. The position eventually advanced in this paper is perhaps closest to that of Clucas (1994).

3 Thanks are due to an anonymous referee for Synthese for encouraging me to make this step explicit. It is unclear what Cavendish scholars would make of it, since they generally do not distinguish between the matter occupying a spatial region, on the one hand, and a part of nature, on the other hand. See, for example, the discussions of infinite divisibility and the doctrine of complete blending at Detlefsen (2006), p. 228 and Detlefsen (2007), p. 169. 
divisibility': as I will show, it is a far cry from what is meant by the phrase when it is used in the course of the popular argument against atomism.

Instead of a geometric notion of division, Cavendish has a dynamic notion of division as a kind of motion that also entails composition: divisions are rearrangements of parts of matter. Infinite divisibility for Cavendish is, therefore, a matter of being big enough to permit infinitely many such motions. To repeat this perhaps surprising claim, infinite divisibility for Cavendish requires being infinitely large, rather than requiring the possibility of infinitely dividing a finite body into smaller and smaller parts. I show in Sect. 3, in support of this interpretation of Cavendish's notions of division and divisibility, that Cavendish's own argument against atomism is really an argument in favor of plenism, and against the existence of vacua. To return to the question of unmixed spatial regions, I note that Cavendish's general theory of motion constrains which rearrangements of parts of matter are possible (i.e., which divisions are possible), such that nothing in her anti-atomism suggests or requires the possibility of divisions that would turn the matter contained in an unmixed spatial region into an unmixed part of nature. So even her commitments to anti-atomism and infinite divisibility seem to be consistent with the existence of unmixed spatial regions.

While Sects. 2-3 are largely devoted to showing that the doctrine of complete blending and Cavendish's anti-atomism do not have to be interpreted to rule out the existence of unmixed spatial regions, in Sect. 4 I nevertheless show that the existence of such regions is to be ruled out on the basis of her theory of place. Since the notion of a spatial region as distinct from a part of nature simply does not appear in Cavendish's theorizing, I suggest that the best we can do is to regard the three types of matter as occupying all of the same places throughout nature. I argue moreover that this view survives scrutiny based on Cavendish's discussing the penetrability of different types of matter without explicitly endorsing overlapping. The paper thus ultimately makes three contributions: first, it establishes that Cavendish has non-geometric theories of parts of nature and of division (Sects. 2-3); second, it offers a little-noted, textually well-grounded account of Cavendish's anti-atomism (Sect. 3); and third, it argues that a surprising interpretation of Cavendish's doctrine of complete blending is to be preferred (Sect. 4).

\section{Cavendish's three-fold materialism}

The signal feature of Cavendish's materialism is her three-fold distinction between types or degrees of matter. In this section, I present that three-fold distinction and consider some of her discussions of motion. The most striking features of those discussions-her commitments to self-motion and occasionalist causation-will not be the focus, as the main concern will be the relationship between the different kinds of matter. At the end of the section, I introduce her metaphorical explanation of how motion occurs, which implicitly suggests that her metaphysics may countenance unmixed spatial regions.

Cavendish first distinguishes between inanimate matter and animate matter. Inanimate matter is matter that cannot move itself, while animate matter is self-moving. She then distinguishes between two types of animate matter, which she calls rational and sensitive. This latter distinction is marked by whether or not the animate matter 
moves inanimate matter: if it does, it's sensitive; if it doesn't, it's rational. But as will be seen, much of her discussion of motion occurs in terms of just the distinction between animate and inanimate matter, so I postpone further examination of the two types of animate matter until the last part of this section.

By the time of $P L$ and $O E P$, Cavendish goes so far as to identify animate matter with (corporeal) self-motion. ${ }^{4}$

... animate matter, was nothing else but corporeal self-motion; and if any difference could be apprehended, it was... between these two degrees, to wit, the animate and inanimate parts of matter, and not between the animate part, and self-motion, which was but one thing, and could not so much as be conceived differently...(OEP, p. 35$)^{5}$

Note that Cavendish here uses 'part' to refer to the animate kind of matter and the inanimate kind of matter. This is a distinct sense of 'part' than the one at issue in the phrase 'part of nature', and I will always use 'type' or 'kind' in place of the usage of 'part' displayed in the $O E P, 35$ passage. ${ }^{6}$

In addition to being identified with self-motion, animate matter is capable of moving inanimate matter. The identification of animate matter with self-motion may then suggest a picture on which animate matter is but a mode of inanimate matter, namely, its motion. But it is important to Cavendish that animate matter, that is, corporeal self-motion, not be regarded as a mode. After attributing the view that motion is a mode to Descartes, she continues as follows:

...in my opinion, there can be no abstraction made of motion from body, neither really, nor in the manner of our conception, for how can I conceive that which is not, nor cannot be in nature, that is, to conceive motion without body? Wherefore motion is but one thing with body, without any separation or abstraction soever. (PL, 1.XXX, p. 97)

\footnotetext{
4 In the 1655 edition of $P P O$, by way of contrast, motion is held to be an inseparable effect of certain kinds of matter: see, e.g., Chap. 41, 18 and Chaps. 61-62, 30. The 1666 edition of $O E P$ explicitly countermands the position expressed in $P P O$ :
}

\begin{abstract}
Whensoever, in my Philosophical Opinions [i.e., PPO], I say Animate Matter and Motion, or the motions of Animate Matter; I do not take them to be two different things, but one and the same; and therefore, both in my Philosophical Letters, and these present Observations, instead of that expression, I say Corporeal figurative Motion; for Self-motion, and Animate Matter, are one and the same thing.
\end{abstract}

Also, when [in PPO] I call the Animate part of Matter the Cause of Motion; I do not mean that considered in general, they are two distinct things, as a Cause and Effect uses [sic] to be; for, as I said before, Self-moving Matter, and Corporeal Self-motion, are equivalent, and signify the same" ("An Explanation of Some obscure and doubtful passages occurring in the Philosophical Works, hitherto published by the Authoresse," p. 46).

5 In addition to the passage quoted here, the identification occurs fairly clearly at ibid., 26, pp. 165, 205206, 207, and 211, as well as at PL, "A Preface to the Reader"; 1.XXX, p. 99; 4.II, p. 420; 4.VI, p. 447; and 4.XXXIII, p. 533.

6 There is another important, and more revealing, terminological choice represented in the passage: Cavendish has abandoned, as potentially misleading, the earlier usage of $P P O$, where the kinds of matter associated with motion were called, among other things, 'spirits'. See OEP, pp. 205-206 for her explicit rejections of immaterialism about motion. 
While Cavendish relies here on the impossibility of conceiving of motion without body, she does not assert the converse. ${ }^{7}$ That is, she does not say that she cannot conceive of body without motion. In GNP she even explicitly distinguishes motion from figure and place on the grounds that body might exist without motion, but not without figure or place. ${ }^{8}$ At times she describes what a world of motionless matter would be like. ${ }^{9}$ But all of this just goes to show that Cavendish identifies motion with a kind of matter, animate matter in particular, and not with body as such.

But the fact that motion is necessarily accompanied by body does not show that it is to be identified with it. To take that step, Cavendish argues that the only way to make sense of the transfer of motion is by identifying motion with (a type of) matter. She repeatedly denies that she can conceive of how motion, were it a mere mode, could be transferred between bodies.

For how can motion, being no substance, but only a mode, quit one body, and pass into another? (PL, 1.XXX, p. 98)

Nay if it were possible, as it is not, that motion could be transferred without matter...then there would be a perpetual and infinite creation and annihilation of substanceless motion, and how there could be a creation and annihilation of nothing, my reason cannot conceive, neither is it possible, unless Nature had more power than God, to create Nothing, and to annihilate Nothing. The truth is, it is more probable for sense and reason to believe a Creation of Something out of Nothing, than a Creation of Nothing out of Nothing (PL, 4.VI, p. 447)

In these passages Cavendish rejects the notion of transferrable modes in general. She subsequently holds that the transfer of motion can therefore only happen via the transfer of matter itself, with which motion is to be identified. ${ }^{10}$

...my opinion is, that if motion doth go out of one body into another, then substance goes too; for motion, and substance or body, as afore-mentioned, are all one thing... Truly, Madam, that neither Motion nor Figure should subsist by themselves, and yet be transferrable into other bodies, is very strange, and as much as to prove them to be nothing, and yet to say they are something. ( $P L$, 1.XXX, p. 98) $)^{11}$

That is, bodies might take on the motion of other bodies, but only if they grow by incorporating their matter, i.e., the bodies themselves.

So it is the combination of considerations about the necessary accompaniment of motion by body and the rejection of the allegedly Cartesian account of motion as a

\footnotetext{
7 It requires some delicate interpretation to reconcile this claim with the doctrine of complete blending as represented in the passages from $O E P$, p. 16 and 158 quoted in Sect. 2 below, but pursuing that interpretive work here would take us too far afield.

8 Compare the end of GNP, 1.I with the opening of 1.II.

9 See, e.g., $P P O$, Ch. 61, 30.

10 Though I will for the time being remain silent on whether what must be transferred is only animate matter, or instead parts of nature composed of all three kinds of matter, Cavendish does seem to allow, in her response to Q. 22 of $O E P$, I.37, that animate matter alone could go from one part of nature into another. 11 See also $O E P$, p. 25.
} 
transferrable mode that grounds her account of motion as a kind of body or material thing. It is fitting, in the context of the present paper, that it is a criticism of what Cavendish explicitly claims to be Descartes's account of the transfer of motion that she relies on to elucidate her metaphysics. ${ }^{12}$ This is fitting, since I will be arguing below that her main argument against atomism differs significantly, and in ways that have yet to be fully appreciated, from the argument against atomism given most famously by Descartes. To connect the foregoing discussion with one of the more exciting features of her metaphysics that I have scarcely mentioned, note that her denial that motion can be a mode that is transferred between bodies is at the bottom not only of her distinctions between kinds of matter, but also of her occasionalist account of causation. She thinks that motion cannot be transferred between bodies without the transfer of matter. She also knows that there are not actually transfers of matter that could explain all of the apparent transfers of motion that we observe in the world. She therefore concludes that the motion of one self-moving part of nature must be the mere occasion for the motion of another self-moving part of nature. ${ }^{13}$

To complete the exposition of Cavendish's threefold materialism, we turn now to her distinction between two kinds of animate matter, which she calls sensitive (animate) matter and rational (animate) matter. Given that both kinds of animate matter must be identified with (self-)motion, it is no surprise that Cavendish sometimes says sensitive matter and rational matter are different "degrees of motion."

The former [i.e., the proponents of Cavendish's official view] answered, that, without question, there were different degrees of motion; for the rational parts were more agile, quick, and subtle in their corporeal actions, than the sensitive, by reason they were of a purer and finer degree of matter, and free from labouring on the inanimate parts...(OEP, p. 33$)^{14}$

In addition to the refined qualities ascribed here to rational matter, the passage also alludes to the jobs that Cavendish assigns to rational matter and sensitive matter. Both sensitive and rational matter, as kinds of animate matter, are self-moving, and inanimate matter is in general said to be moved by animate matter. But it is sensitive matter in particular that is assigned the role of moving, "labouring on," inanimate matter. Rational matter, by way of contrast, merely directs the proceedings. The following passage from GNP makes clear that the laboring role of sensitive matter is its distinguishing characteristic:

there can be but two sorts of the Self-moving Parts; as, that sort that moves entirely without Burdens, and that sort that moves with the Burdens of those Parts that are not Self-moving (GNP, 1.III, p. 3)

So it is sensitive matter that moves inanimate matter. But given that motion cannot be transferred between bodies, it is hard to see how sensitive matter can do anything at all to inanimate matter.

\footnotetext{
12 But cf. Hatfield (1979) for discussion of Descartes's actual views on the transfer of motion.

13 For more on Cavendish's occasionalist causation, see James (1999), pp. 231-239; O’Neill (2001), pp. xxix-xxxv; and Detlefsen (2007), Sect. 3 and (2009), Sect. 2.

14 See also GNP, 1.V, pp. 4-6 and 1.XV, pp. 13-15.
} 
Cavendish offers a metaphorical explanation of this part of her view.

First, they [i.e., imagined opponents of Cavendish's official view] asked, How it was possible, that that part of matter which had no innate self-motion, could be moved? For, said they, if it be moved, it must either be moved by its own motion, or by the motion of the animate part of matter: By its own motion it cannot move, because it has none: but if it be moved by the motion of the animate, then the animate must of necessity transfer motion into it; that so, being not able to move by an innate motion, it might move by a communicated motion.

The former thoughts [i.e., the proponents of Cavendish's official view] answered, that they had resolved this question heretofore, by the example of a horse and a man, where the man was moved and carried along by the horse, without any communication or translation of motion from the horse into the man: Also a stick, said they, carried in a man's hand, goes along with the man, without receiving any motion from his hand. (OEP, pp. 26-27)

I take it that the point of these metaphorical explanations is that neither the horse nor the hand begin with a quantity of motion which is lost through the transfer of motion to the rider or the stick. Consider how Cavendish rejects the transfer of motion on a modal conception: she does not think "that one body can give or transfer motion into another body; and as much motion it gives or transfers to that body, as much loses it" ( $P L, 1 . \mathrm{XXX}$, pp. 97-98). So it is plausible that she prefers these examples, in contrast to examples involving, say, colliding billiard balls, because the horse carries the rider with it as it begins to move, as does the imagined hand with its stick. There is no initial motion, and there is no collision that stops the horse or the hand. So Cavendish can hold that there is no transfer of motion between parts of nature-no part of nature that gives its previously existing quantity of motion, thereby losing it, to another part of nature - to be found in these examples. But there is a second reason that there is no transfer of motion between parts of nature when sensitive matter moves inanimate matter: since parts of nature must be completely blended, sensitive matter together with the inanimate matter it moves are components of a single part of nature. ${ }^{15}$ To further elucidate this claim, we turn to the doctrine of complete blending itself.

\footnotetext{
15 Although a fully satisfactory discussion of Cavendish's account of how inanimate matter is moved is beyond the scope of this paper, note that she says that animate matter 'forces or causes' (PL, 1.XXX, pp. 99) inanimate matter to move, and also that animate matter 'can only occasion' (OEP, p. 27) inanimate matter to move. Moreover, she explicitly says, at both of the cited locations, that this forcing, causing, or occasioning does not count as the communication of motion. My proposal is that the two reasons given in the main text reveal the crucial thoughts justifying the idea that these claims can both be consistently maintained. (An alternative possibility, which I do not have the space to pursue here, is that inanimate matter is unmotivated to move on its own, though it can be inspired to do so by animate matter. A serious challenge for this alternative interpretation is that it requires interpreting Cavendish as equivocating on 'self-motion' in a way for which there is, to my knowledge, no independent textual evidence.) Thanks to an anonymous referee for Synthese for pressing me to say a bit more here.
} 


\section{Cavendish on parts of nature: the doctrine of complete blending}

According to Cavendish's doctrine of complete blending, all parts of nature are composed of a mixture of the three kinds of matter. In this section, I consider that doctrine with an eye towards understanding how Cavendish individuates parts of nature. I focus in particular on whether the matter occupying an arbitrary spatial region is guaranteed to count as a part of nature. I will argue against the presumption of such a guarantee, by showing that parts of nature are individuated as the effects of natural motions. This standard for individuating parts of nature ensures that sensitive matter and the inanimate matter it moves are both components of the same part of nature. It also ensures that the doctrine of complete blending is not, by itself, incompatible with the existence of unmixed spatial regions.

Cavendish often describes the doctrine of complete blending in connection with inanimate and animate matter broadly speaking.

...there can be no part or particle of this composed body of nature, were it an atom, that may be called inanimate, by reason there is none that has not its share of animate, as well as inanimate matter, and the commixture of these degrees is so close, it is impossible one should be without the other. (OEP, p. 16)

...these degrees or parts of matter, were so closely intermixt in the body of nature, that they could not be separated from each other, but did constitute but one body, not only in general, but also in every particular; so that not the least part (if least could be) nay not that which some call an atom, was without this commixture; for, wheresoever was inanimate, there was also animate matter...(OEP, pp. 34-35)

...there is such a commixture of animate and inanimate matter, that no particle in nature can be conceived or imagined, which is not composed of animate matter, as well as of inanimate...(OEP, p. 158)

There is no such thing as simple bodies in nature; for if nature herself consists of a commixture of animate and inanimate matter, no part can be called simple, as having a composition of the same parts. $(O E P, \text { p. } 271)^{16}$

But the doctrine also applies more specifically to rational and sensitive matter, the two subtypes of animate matter that Cavendish identifies.

...nature is an infinite composition of rational, sensitive and inanimate matter: which although they do constitute but one body, because of their close and inseparable conjunction and commixture; nevertheless, they are several parts, (for one part is not another part) and therefore every part or particle of nature, consisting of the same commixture, cannot be single or indivisible. $\left(O E P\right.$, p. 127) ${ }^{17}$

According to O'Neill (2001), the doctrine of complete blending immediately gives rise to the interpretive question that I am interested in here. After quoting Cavendish's claim that "no particle in nature can be conceived or imagined, which is not composed

\footnotetext{
16 Note that the passage-ending word 'parts' here refers to types of matter.

17 See also $O E P$, p. 99, 157, and 207. Note that the first three occurrences of 'part(s)' in the quoted passage refer to types of matter, though 'part or particle of nature' does not.
} 
of animate matter, as well as of inanimate," O'Neill immediately asserts that "the mixture of animate and inanimate nature is not simply a juxtaposition or meeting at a surface" (xxv). ${ }^{18}$ She then justifies this assertion by a reductio ad absurdum argument. If the doctrine of complete blending allowed "juxtaposition or meeting at a surface," that is, if it allowed animate and inanimate matter to occupy extended, spatially distinct areas, it would be possible to pick a region of one of the areas that contained only animate or only inanimate matter. But that unmixed spatial region would then contain a non-blended particle of nature, i.e., a particle of nature that contained only animate or only inanimate matter, which clearly contradicts Cavendish's claim.

O'Neill's reductio relies on a presupposition about particles of nature for which she nowhere argues. Namely, it presupposes that the matter found in any region of space composes a particle of nature. Call this the crucial presupposition of the reductio argument. If the crucial presupposition is to be rejected, then a reconstruction of Cavendish's doctrine of complete blending can allow that the mixture of animate and inanimate nature is merely the juxtaposition of unmixed regions of rational, sensitive, and inanimate matter. Particles as such of course have to be blended, but that does not mean that arbitrary regions of space must be. (I will ultimately argue, in Sect. 4, that there are no unmixed spatial regions-but for rather different reasons than those considered here.)

A major contention of this article is that Cavendish's theories of parts of nature and division, when properly understood, do not license the crucial presupposition of O'Neill's reductio. If that contention is right, then O'Neill's account of the doctrine of complete blending stands in need of revision. To support the contention, close attention will be paid to Cavendish's comments on parts of nature and division. But it must be admitted that the waters are muddied by Cavendish herself appearing to equivocate. She sometimes appears to use 'divisible' and related words in what we might call the Cartesian geometric sense of having extension and therefore being, at least in principle, subject to separation. ${ }^{19}$ But more often she talks about 'division' as a particular kind of motion, which she typically pairs with 'composition,' and which can be thought of, again in Cartesian terms, as change of external place. ${ }^{20}$ An associated sense of 'dividable' (or 'divideable', or, as in some occurrences in GNP, 'divisible'), which is paired with 'composable' (or 'composeable', or, in GNP, 'compoundable'), refers

\footnotetext{
18 This argument reappears unchanged in O’Neill (2013), 315.

19 The best example of Cavendish appearing to use 'divisible' in this sense occurs at $O E P$, p. 125, where she says that "whatsoever has body, or is material, has quantity, and what has quantity, is divisible." See also her use of 'individable' in the passage from PL, 4.IX, p. 455 quoted below. While these are the best examples of this usage, I am somewhat inclined to read Cavendish as deliberately equivocating in the $O E P$ passage, with a wink to the reader, a point to which I return in the discussion of the "logico-mathematical argument" below. (The 1666 edition of $O E P$ has 'divideable' [sic] rather than the 'divisible' of the 1668 text, and only uses 'divisible' in echoes of quoted material in the third section of the book, where Cavendish comments on the thought of ancient philosophers, and where the intention is presumably to use the geometric sense. In 1668's GNP, moreover, she seems to use 'dividable' [with the 'e' now omitted] and 'divisible' interchangeably, and always in the second sense that I am about to introduce. So I take it that there is no philosophically significant difference between the meanings of 'divideable' and 'divisible' on her 1666 usage.).

20 Cavendish uses 'division' in this sense in all of its occurrences in the quotations reproduced below. For the Cartesian notion of external place, see Descartes, Principles of Philosophy, II.13-15.
} 
to actually (not merely conceivably) being subject to these dividing (and composing) motions. ${ }^{21}$ She also uses 'part' in a number of senses, though we will be able to get a grip on her view if we focus on one particular use of 'part' which is at play in her talk of 'natural parts' or 'parts of nature'. (My preferred locution is 'parts of nature' because that is the phrase Cavendish uses in her arguments against atomism that figure centrally in the next section.)

Our immediate goal is to get clear on Cavendish's claim about particles of nature at $O E P$, p. 158, the passage on which O'Neill relies in her characterization of the doctrine of complete blending. While Cavendish does not elaborate a theory of particles of nature, she does have a theory of parts of nature. If we can rely on the plausible assumption that 'particle' is just a façon de parler for talking about small parts, then getting clear on the theory of parts of nature will allow us to evaluate O'Neill's crucial presupposition. ${ }^{22}$ On her theory of parts of nature, part of nature is primarily a causal notion. In saying that it is primarily a causal notion, I mean to distinguish it from a purely geometrical notion of a part. The geometrical notion of a part is what does the work in O'Neill's account of the doctrine of complete blending: recall that the crucial presupposition is that the matter found in any region of space composes a particle of nature.

On my view, parts of nature are for Cavendish effects of nature's self-motion. Her own explicit positive characterizations of this causal notion of a part of nature come in passages that describe her doctrine of complete blending.

when I say, no creature in nature can be called prime or principal, I understand natural effects, that is, natural composed parts or creatures: as for example, all those finite and particular creatures that are composed of life, soul and body, that is, of the animate both rational and sensitive, and the inanimate parts of matter (OEP, p. 205)

those figures which are composed of the aforesaid animate and inanimate parts of matter... are no more but effects (OEP, p. 206)

In both of these passages, Cavendish describes the completely blended parts of nature ("natural composed parts or creatures" and "figures") as effects. ${ }^{23}$ The context of the second passage suggests that the cause of these effects is self-moving matter, and Cavendish provides plenty of independent confirmation of this contextual inference elsewhere.

\footnotetext{
21 See, e.g., the passage from $P L, 2 . I V$, p. 144 quoted below, as well as GNP, 1.IV, p. 4.

22 Cavendish's usage of 'particle' in at least $P L, O E P$, and GNP supports understanding 'particle' in this way. For example, the first three occurrences of 'particle' in $P L$ appear in the phrase 'little particles'; four occurrences appear in the constructions 'part and particle' or 'part or particle'; and the rest appear in quotations or echoes of other authors with the single exception of the phrase 'every particle of every creature', which appears at $P L, 2 . X X X$, p. 223. Further, as Stewart Duncan (p.c.) has pointed out to me, 'particle' occurs in GNP only in the phrases 'part and particle' and 'part or particle'. The usage of 'particle(s)' in $O E P$ is somewhat more varied, but the assumption remains plausible. Of roughly 55 occurrences, 19 appear in the phrases 'part and particle' or 'part or particle', and an additional 15 are in contexts where the smallness of the particles is made fairly explicit.

23 Cf. the description of the formation of matter into parts as "the genuine effect of variously determined motion"- though not of the individual parts as effects-at Boyle (1991), p. 20.
} 
Nature being material, is composable and dividable, which is the cause of so many several Creatures, where every Creature is a part of nature...Nature is a self-moving substance, and by self-motion divides and composes her self several manners or ways into several forms and figures ( $P L, 2 . I V$, p. 144)

The truth is, there is nothing prime or principal amongst the effects of nature, but only the cause from which they are produced, which is self-moving matter $(O E P, \text { p. } 234)^{24}$

She contrasts the caused status of these parts of nature with bodies "not otherwise united but by a bare "apposition"" (OEP, p. 231). ${ }^{25}$ The grounds of the unity of such parts of nature, then, is not apposition, but their formation via self-movement. This does not immediately rule out parts of nature being composed of juxtaposed unmixed spatial regions. It just requires that the inanimate material component of a part of nature was moved into its place, wherever that is, by the sensitive material component of that same part. Call this theory of parts of nature, on which they are individuated by their causal histories in this way, the causal conception of parts of nature.

The causal conception of parts of nature is a metaphysical theory, a theory that identifies parts of nature with effects of motion. ${ }^{26}$

when I speak of parts of nature...I conceive nature to be an infinite body, bulk or magnitude, which by its own self-motion, is divided into infinite parts; not single or indivisible parts, but parts of one continued body, only discernible from each other by their proper figures, caused by the changes of particular motions... all motions that are in nature, are within herself; and being various and infinite in their changes, they divide the substance or body of nature into infinite parts; for the parts of nature, and changes of motion, are but one thing...(OEP, pp. 125126)

It is this metaphysical account of parts as effects that explains her drawing of what is otherwise a very mysterious analogy between the whole-part relation and the causeeffect relation.

There is no other difference between self-knowledge, and particular knowledges, than betwixt self-motion, and particular self-actions; or betwixt a whole, and its parts; a cause, and its effects: for, self-knowledge is the ground and principle

\footnotetext{
24 See also $O E P$, pp. 126, 138, 157, and 165.

25 It seems clear from a footnote that O'Neill appends to this sentence that she takes this passage to support her interpretation of the doctrine of complete blending (ibid., p. 231, fn. 146). But I hope my alternative interpretation will shortly become clear.

26 Detlefsen (2006), pp. 213-214 also gives a similar account of the individuation of "finite individuals" in Cavendish. I take Cavendish's theory here to bear strong similarities to Spinozistic and Cartesian modal theories of individuation: see the discussion of Ethics 1p15s at Bennett (1996), Sect. 6, as well as the account of Descartes's theory of individuation in a plenum given by Francks (2003), Ch. 2. But since Cavendish rejects modes, there are additional interpretive puzzles lurking here. The useful discussion of the individuation of everyday objects in Cavendish at Lascano (2015), Sect. 2.7 includes a comparison with Hobbes, and I myself touch on these matters in a work-in-progress focused on different notions of substance latent in Cavendish's metaphysics.
} 
of all particular knowledges, as self-motion is the ground and principle of all particular actions, changes and varieties of natural figures. (OEP, p. 138)

On Cavendish's view, self-moving matter, i.e., the whole of nature, is the cause of the parts of nature, i.e., the effects of self-moving matter's rearrangement of itself.

The causal conception of parts of nature can help inform our reading of the passage at $O E P, 158$ on which O'Neill relies. When Cavendish says, in that passage, that "there is such a commixture of animate and inanimate matter, that no particle in nature can be conceived or imagined, which is not composed of animate matter, as well as of inanimate," we have to understand her as, in the first place, making a claim about how parts of nature can be, rather than a claim about how regions of space can be. Parts of nature are effects of self-moving matter. Since parts of nature are effects of self-moving matter, and self-moving matter is itself composed of both animate matter and inanimate matter, it is no surprise that the resulting effects are similarly composed. Indeed, the $O E P, 158$ passage itself occurs in the context of an explanation of how animate matter can move inanimate matter. It is only in that context that Cavendish asserts the inconceivability of what we might call non-blended particles of nature. ${ }^{27}$ But this does not license the crucial presupposition of O'Neill's reductio. On the contrary, arbitrary subregions of parts of nature will only count as part(icle)s of nature if they are themselves effects of self-moving matter. Establishing that they are is an additional burden to be met in order to reach O'Neill's conclusion that complete blending is not a matter of "juxtaposition or meeting at a surface" (xv).

Meeting the burden requires an account of the individuation of effects of selfmoving matter. Given that Cavendish takes the doctrine of complete blending to apply to the actual world, the actual effects of self-moving matter must contain both animate and inanimate matter. But the horse-rider analogy that Cavendish uses to explain how animate matter moves inanimate matter seems to tell against the claim that arbitrary subregions of parts of nature contain both animate and inanimate matter. A horse (representing animate matter) and its rider (representing inanimate matter) occupy spatially distinct, juxtaposed regions that meet at their surfaces. It is obvious that there are subregions of the mereological sum of the horse and its rider that are wholly contained

\footnotetext{
27 More generally, the literature does not appreciate what I take to be the clear contingency of the doctrine of complete blending. Consider Cavendish's boldest assertion of the supposed necessity of the doctrine of complete blending:

this "triumvirate" of the degrees of matter, is so necessary a constitutive principle of all natural effects, that nature could not be without it; I mean, nature considered, not what she might have been, but as she is $(O E P$, p. 158)
}

Despite the occurrence of 'necessity' in this passage, Cavendish immediately limits the application of her claim to the actual world. And despite Cavendish's oft-quoted claims about inconceivability, it is the contingency of the doctrine of complete blending that explains her willingness, mentioned already in Sect. 1, to give descriptions of worlds composed of only inanimate matter. She also sometimes describes what a world of nothing but corporeal self-motion would be like, as at OEP, pp. 35-36 and pp. 157-158. In GNP, her explicit consideration of whether there could be worlds composed solely of one or another type of matter terminates in the claim that the types of matter "would not divide from each other, if they could" (Appendix 2.I). This leaves open the possibility of worlds in which the types of matter are not completely blended because they weren't completely blended from eternity, and therefore never had to divide from each other in order to exist separately. 
within the rider, and likewise for the horse. The spatial arrangement represented by the horse and its rider is nevertheless consistent with the doctrine of complete blending if (but only if) the horse and its rider together represent only one effect of self-moving matter.

Further, the horse and rider do represent only one effect of self-moving matter. Recall that the horse represents animate matter, and the rider represents inanimate matter. It is only by considering them as a unit that they represent an effect of selfmoving matter that vindicates the doctrine of complete blending. That's why I was able to deny, at the end of Sect. 1, that the movement of the rider by the horse counts as a transfer of motion between two distinct parts of nature. But more importantly, taking the analogy seriously as a representation of the spatial disposition of different types of matter within a single part or effect of nature helps us see how the crucial presupposition of O'Neill's argument can fail. The doctrine of complete blending is, for all that has been said so far, consistent with the existence of unmixed spatial regions.

But it is open for the partisan of O'Neill's account of the doctrine of complete blending to hold that the analogy breaks down when it comes to the spatial arrangement of different types of matter. That strategy would be especially plausible if Cavendish's argument against atomism required that parts of nature were infinitely divisible into ever smaller parts of nature. The next section is devoted to arguing that Cavendish's argument against atomism requires no such thing.

\section{Cavendish on division: an argument against atomism}

Cavendish's commitment to the infinite divisibility of nature may seem likely to settle the question whether arbitrary subregions of parts of nature are themselves also parts of nature. If Cavendish thinks that matter can be arbitrarily subdivided into different parts of nature, then the answer must be yes. But Cavendish's comments on infinite divisibility are difficult to interpret along these lines. In fact, in light of the causal conception of parts of nature, Cavendish has to be interpreted as giving a largely unappreciated argument against atomism. In this section, I examine Cavendish's argument against atomism in $O E P, 1$.XXXI. Along the way, I present Cavendish's dynamic conception of division, her non-Cartesian account of infinite divisibility, and what I take to be the three central tenets of the primary anti-atomistic argument of 1.XXXI. I also argue that these tenets are actually consistent with a kind of atomism, which I call plenist-vitalist atomism, against which she does not deploy an argument based on infinite divisibility, but instead what Detlefsen (2006) calls "the normative argument against atomism." The upshot of this section for the overarching concerns of the paper is that Cavendish's anti-atomism does not provide clear support for the crucial presupposition of O'Neill's reductio, and is not necessarily inconsistent with the existence of unmixed spatial regions.

Detlefsen (2006) distinguishes the normative argument against atomism from what she calls "the logico-mathematical argument" against it. The normative argument says that "atoms, as freely acting beings, would produce disorder in nature, and 
yet we experience nature as orderly," so atomism seems to be false. ${ }^{28}$ But it is the logico-mathematical argument that will concern us for the coming paragraphs. ${ }^{29}$ It is essentially the Cartesian argument against atomism. I quote here his familiar passage:

We also easily understand that it is not possible for any atoms, or parts of matter which are by their own nature indivisible, to exist. The reason is that if there were any such things, they would necessarily have to be extended, no matter how tiny they are imagined to be. We can, therefore, still conceive of each of them being divided into two or more smaller ones, and thus we know that they are divisible. (Principles of Philosophy, I.20, Miller and Miller translation)

Cavendish gestures at this argument at the beginning of section I.31 of OEP, titled "Of the Parts of Nature, and of Atoms." 30

...there can be no atom, that is, an indivisible body in nature; because whatsoever has body, or is material, has quantity; and what has quantity, is divisible. (OEP, p. 125)

It is hard to deny that Cavendish is here dutifully reciting a version of the Cartesian argument against atomism. ${ }^{31}$ Indeed, Detlefsen (2006) presents this passage as evidence for Cavendish's "implicit mathematical belief in the infinite divisibility of matter" (204).

But the progression of $O E P$, I.31 makes little sense, if that is all Cavendish is doing. She continues:

But some may say, If a part be finite, it cannot be divisible into infinite. To which I answer, that there is no such thing as one finite single part in nature: for when I speak of the parts of nature, I do not understand, that those parts are like grains of corn or sand in one heap, all of one figure or magnitude, and separable from each other: but, I conceive nature to be an infinite body, bulk or magnitude, which by its own self-motion, is divided into infinite parts (OEP, pp. 125-126)

If Cavendish were attempting an exposition of the logico-mathematical argument against atomism, if she were evincing Detlefsen's "implicit mathematical belief," then she would just say that finite parts certainly can "be divisible into infinite." But she does not say this, instead changing the subject to her causal conception of parts of nature and an associated conception of division. Cavendish confirms, only a few lines later, that it is these distinctive notions that she has in mind: "the motions that are in nature...divide the substance or body into infinite parts; for the parts of nature, and changes of motion,

\footnotetext{
28 Detlefsen (2006), p. 201.

29 To my knowledge, Detlefsen's account of Cavendish as giving the logico-mathematical argument has not been criticized in the literature. It is explicitly accepted at Marshall (2014), Sect. 2a.

30 See Detlefsen (2006), p. 204.

31 To be clear, I'm not sure that one need grant that Cavendish actually believes this argument, or even that she intends to be giving it in its usual form. Perhaps Cavendish intends her reader to pick up on a deviant use of 'divisible', even in this instance. Cf. fn. 19 on Cavendish's use of 'divisible' and related words, and the possibility of deliberate equivocation here.
} 
are but one thing" (126). Cavendish goes on to give a distinctive argument against atomism based on these notions, which can and should be distinguished not only from her normative argument, but also from the logico-mathematical argument. ${ }^{32}$

The notion of division that Cavendish has in mind here is a dynamic one. It is the notion of a particular kind of motion or action of self-moving matter.

... all composition and division, contraction, dilatation, nay, even retention, are local motions (OEP, p. 28)

...for dilatation and composition, as also division and contraction, are different actions. ...The truth is, as division and composition, are natural corporeal motions, so are contraction and dilatation (OEP, p. 125)

In particular, division is the motion of a part of nature away from its current surroundings, but not only away from its current surroundings. It is, at the very same time, the motion of a part of nature into new surroundings. Division is thus always paired with the action of composition.

...there is as much composition, as there is division in nature; and as soon as parts are divided from such or such parts, at that instant of time, and by the same act of division, they are joined to all parts, and all this, because nature is a body of a continued infiniteness, without any holes or vacuities. (OEP, p. 127)

The chief and general actions of nature, are division and composition of parts, both which are done but by one act; for at the same time, when parts separate themselves from such parts, they join to other parts...(OEP, p. 192) $)^{33}$

Because division entails composition for Cavendish, infinite divisibility, as she conceives of it, is not a matter of the possibility of further subdividing any part of nature, however small, as it is for Descartes.

In fact, Cavendish explicitly claims that infinitely dividing individual parts is impossible.

But when [Thomas Hobbes] says, there cannot be an Infinite and Eternal Division, [it] is very true, viz., in this sense, that one single part cannot be actually infinitely divided, for the Compositions hinder the Divisions in Nature, and the Divisions the Compositions, so that Nature, being Matter, cannot be composed so, as not to have parts, nor divided so, as that her parts should not be composed, but there are nevertheless infinite divided parts in Nature, and in this sense there may also be infinite divisions...(PL, 1.XV, p. 51)

And thus, when [Henry More] mentions in another place, That if a body be divisible into Infinite Parts, it hath an Infinite number of extended parts: If by extension he mean corporeal dimension, I am of his opinion; for there is no part, be it never so little in Nature, but is material; and if material, it has a body; and if a body, it must needs have a bodily dimension; and so every part will

\footnotetext{
32 O'Neill (2001), xxvi briefly considers this third argument, but her focus quickly shifts to a version of what Detlefsen calls the normative argument.

33 See also passages at $O E P$, pp. 37, 232, and 263.
} 
be an extended part: but since there is no part but is finite in its self, it cannot be divisible into infinite parts; ...nevertheless, there are...infinite divisions [in Nature] because there are infinite divided parts...(PL, 2.IX, pp. 158-159)

Detlefsen argues that we can discount these passages. Since they come from Philosophical Letters, which was published in 1664, Cavendish's position might have matured by the time the first edition of Observations on Experimental Philosophy was published in 1666. Detlefsen argues that, in fact, Cavendish's position had changed, as evidenced by her recitation of the Cartesian argument against atomism, together with the implicit acceptance of a geometric notion of infinite divisibility that the Cartesian argument entails. ${ }^{34}$

But there seem to me to be two problems with this view. First, passages similar to those from $P L$ that Detlefsen argues we should discount occur in $O E P$ itself. Cavendish does not change her mind about whether compositions and divisions "hinder" one another in a way that prevents the infinite division of a single part of nature.

The infinite compositions and divisions hinder, that nature cannot run into extremes in her particulars, but keep the parts and actions of nature in an equal balance. (OEP, p. 192)

Neither does she change her mind about the connection between infinite divisibility and the infinity of parts that together make up nature as an infinite whole, as the passage from $O E P$, pp. 125-126 quoted at the beginning of this section shows. Further, in a section of the first edition of $O E P$ where Cavendish offers clarifications of her views as expressed in $P P O$ and $P L$, she explicitly discusses what she means in calling nature "infinite" but passes up the opportunity to suggest that her view about infinite divisibility has changed. ${ }^{35}$ So the later Cavendish may well accept the $P L$ passages.

Second, there is the possibility that Cavendish was equally willing to endorse the logico-mathematical argument even in 1664. She seems to allude to it in $P L$ itself, in the course of a brief rejection of Charleton's atomism.

Concerning [Charleton's] argument of Divisibility of Parts, my opinion is, That there is no Part in Nature Individable, no not that so small a part, which the Epicureans name an Atom (PL, 4.IX, p. 455)

One possibility is that, in the brief moments when Cavendish alludes to the logicomathematical argument, she is merely paying lip service to standard anti-atomist arguments that play no actual role in her metaphysical theorizing. ${ }^{36}$ A somewhat more palatable possibility is that, when Cavendish says that anything with quantity has parts, and that even a part of nature as small as an Epicurean atom is divisible, she means that they are subject to division in her dynamic sense. That is, she could hold that some portion of their animate matter could indeed move some portion of their inanimate

\footnotetext{
34 Detlefsen (2006), pp. 204-206.

35 See "An Explanation of Some obscure and doubtful passages occurring in the Philosophical Works, hitherto published by the Authoresse," pp. 47-48.

36 Compare her one-line allusion at GNP, 1.IV, 4 to the Cartesian argument against the vacuum, an argument which is entirely missing from her lengthier arguments against the void in $O E P$.
} 
matter away from the rest. ${ }^{37}$ But that is consistent with the existence of unmixed spatial regions. Moreover, infinite divisibility, even in the sense of the logico-mathematical argument, does not guarantee arbitrary divisibility, and Cavendish certainly never says that arbitrary subregions of a part of nature can be divided from the rest.

But to be clear, division, even when Cavendish talks of infinite division and infinite divisibility, entails composition.

When I say, that "one finite part can undergo infinite changes and alterations"...I mean, one part may be infinitely divided and composed with other parts; for as there are infinite changes, compositions, and divisions in nature, so there must be of parts; there being no variety but of parts; and though parts be finite, by reason they have limited and circumscribed figures; nevertheless, as for duration, their parts being the same with the body of nature, are as eternal, and infinite as nature herself, and thus are subject to infinite and eternal changes. (OEP, p. 18)

Every particular part or figure is infinitely divided and composed from, and with other parts. (OEP, p. 192)

In the first passage quoted here, Cavendish suggests that parts of nature are, or at least could be, divided and composed with other parts infinitely many times over the course of their eternal existence. But she also thinks that nature is, at any given time, divided into, and hence composed of, infinitely many parts. Cavendish takes this to require that nature is infinitely large. Thus in her critical discussion of Thales in the third part of Observations on Experimental Philosophy, Cavendish presents the following argument:

As for the world, that there is but one, I do willingly grant it, if by the world he did mean nature; but then it cannot be finite. But Thales seems to contradict himself in this theorem, whenas he grants, that bodies are divisible in infinite: for, if there be infinite actions, as infinite divisions in nature, then surely the body of nature itself must be infinite. $(O E P, \text { p. 251.) })^{38}$

If the existence of infinitely many (finite) parts requires nature to be infinite, then (at least infinitely many of) the parts themselves must have some non-infinitesimal size. Moreover, if this is what Cavendish has in mind when she talks about infinite divisibility in arguing against atomism, then her anti-atomism must not, pace Detlefsen (2006), rely on "a necessary commitment to the infinite divisibility of matter" (207). She must be giving a different argument in $O E P, 1 . \mathrm{XXXI}$.

She is. She presents three tenets of her anti-atomism in 1.XXXI. What she rejects, firstly, is that there are a bunch of identical building blocks of nature.

...it is evident, first, that no certain quantity or figure can be assigned to the parts of nature, as I said before of the grains of corn or sand...(OEP, p. 126)

Her claim here is connected to her basic metaphysics: there are no fundamental building blocks in nature, except for self-moving matter. Cavendish critically discusses a variety

\footnotetext{
37 Cf. fns. 19 and 31.

38 See also $O E P$ pp. 31-32 here.
} 
of theories of such fundamental building blocks in $O E P, 2 . \mathrm{XX}$. She considers and rejects theories according to which everything is composed, e.g., of fire, air, water, and earth; of just water; of salt, sulphur, and mercury. Her own view is reported in a passage that has already been quoted once above.

The truth is, there is nothing prime or principal amongst the effects of nature, but only the cause from which they are produced, which is self-moving matter...(OEP, p. 234)

So the first tenet of her anti-atomism is her fundamental conception of nature, which depends on neither the logico-mathematical argument nor her distinctive theories of parts of nature and division.

Secondly, she rejects that there are single parts of nature, where the notion of a single part is given a very particular elaboration.

Next, [it is evident] that it is impossible to have single parts in nature, that is, parts which are indivisible in themselves, as atoms; and may subsist single or by themselves, precised or separated from all other parts...(OEP, p. 126)

This second tenet does depend on her theory of division. Because division entails composition, there is no way for any part of nature to be "precised or separated" from the rest of nature. Rather, every part of nature is part of a larger figure as well: eyes are parts of heads, heads are parts of animals, animals are parts of earth, and so on. The rejection of single parts being "indivisible in themselves" is explained via the doctrine of complete blending.

Nay, were it possible that there could be a single part, that is, a part separated from all the rest; yet being a part of nature, it must consist of the same substance as nature herself; but nature is an infinite composition of rational, sensitive and inanimate matter: which although they do constitute but one body, because of their close and inseparable conjunction and commixture; nevertheless, they are several parts, (for one part is not another part) and therefore every part or particle of nature, consisting of the same commixture, cannot be single or indivisible.

(OEP, p. 127)

This is a striking passage. It makes clear that single parts are defined as parts "separated" from the rest of nature. It also makes clear that the several "parts" of which a "single part" is here held to consist are not smaller parts of nature, that is, not smaller effects of self-moving matter. Rather, recall from Sect. 1 that Cavendish sometimes uses 'part'-talk for the types of matter. The "several parts" that Cavendish here describes are the rational, sensitive, and inanimate matter of a part of nature, the three kinds of matter from which any part of nature is and must be composed. ${ }^{39}$ She again connects her rejection of single parts with the presence of self-motion, i.e., animate matter in the closing sentence of $O E P, 1 . \mathrm{XXXI}$.

\footnotetext{
39 See also $O E P$, p. 168 for a passage in which Cavendish makes similar comments about atoms, requiring that even they would have to contain rational, sensitive, and inanimate matter.
} 
Lastly, as there is a perpetual self-motion in nature, and all her parts, so it is impossible that there can be...single parts in nature. (131)

Cavendish is thus not arguing that single parts are divisible in a geometric sense because they are extended; she is not giving the logico-mathematical argument. Her equivocation on 'part' in the striking $O E P$, p. 127 passage is a direct consequence of the fact that is giving a different argument against atomism. ${ }^{40}$

To return to the list of tenets of Cavendish's anti-atomism, thirdly, she rejects the existence of vacua.

All which proves, that there are no single parts, nor vacuum, nor no composition of loose atoms in nature; for if such a whole and perfect figure would be divided into millions of other parts and figures, yet it is impossible to divide it into single parts, by reason there is as much composition, as there is division in nature; and as soon as parts are divided from such or such parts, at that instant of time, and by the same act of division, they are joined to other parts...(OEP, p. 127)

Her rejection of the vacuum is presented as coming for free alongside her rejection of single parts of nature. It, too, depends on her theory of division as entailing composition.

These three tenets of Cavendish's anti-atomism - the rejection of fundamental building blocks or principles of nature other than self-moving matter, the rejection of single parts, and the rejection of vacua-suffice to establish that Cavendish rejects the existence of atoms in a void. To be more precise, only the latter two tenets are required to establish that she is a plenist. But her anti-atomism, as described thus far, leaves room for a theory that may well deserve to be called atomism, subject to two provisos. First, the so-called atoms would have to fill all of nature, in which case "nature would be like a beggar's coat full of lice" (OEP, p. 129). Second, the atoms would have to contain rational, sensitive, and inanimate matter: they would have to be "self-moving, living and knowing bodies" (OEP, p. 129). To label this view, call it plenist-vitalist atomism. Plenist-vitalist atomism is, Cavendish says, "fitter for a poetical fancy, than for serious philosophy; and this is the reason I have waived it in my philosophical works" (129). ${ }^{41}$ She then gives what Detlefsen (2006) calls the normative argument against atomism to reject it. But it is noteworthy that Cavendish does not treat it as already ruled out by her earlier argument against atomism. She does not do so precisely because she is not giving the logico-mathematical argument against atomism-which is, as Detlefsen (2006) notes, fully "decisive"-but a distinctive argument that merely rules out what she calls single parts and concludes that the world is a plenum (207).

There is a further difference between the Cartesian logico-mathematical argument and Cavendish's argument against atomism. While Descartes allows that there may

\footnotetext{
40 Her willingness to equivocate on 'part' also explains how she is able to compare figures as to whether they have more or fewer parts, while simultaneously holding that all parts have parts of their own, at $O E P$, p. 234.

41 As Marcy Lascano (p.c.) has pointed out to me, Cavendish is here distancing herself from the atomistic poems of $P F$, but nevertheless I take it to be significant that she does not reject plenist-vitalist atomism on the basis of the logico-mathematical argument.
} 
be limits to our own powers to divide extended objects, God at least must have the ability to divide any extended object whatsoever, no matter how small it might be.

Moreover, even if we imagine that God wished to create a particle of matter which was impossible to divide into smaller ones; that particle could not, even then, be properly called indivisible. For even supposing that He has made it such that no created being could divide it, He certainly cannot have deprived Himself of His ability to divide it; because, as we noticed earlier, it is absolutely impossible for Him to diminish His own power. Therefore, strictly speaking, this particle will remain divisible, since it is so by virtue of its own nature. (Principles of Philosophy, I.20, Miller and Miller translation)

The distinction between what we can divide and what God can divide can be explicated in terms of a distinction between what is physically divisible and what is metaphysically divisible, respectively. Descartes's own argument against atomism establishes only that all particles of matter, qua essentially extended, are metaphysically divisible, even if dividing them is physically impossible. So Descartes makes room for particles of matter that it is physically impossible to divide. But Cavendish argues explicitly that there are actually no single parts. Since division entails composition, it is physically impossible for a part of nature to become "precised or separated" from the rest of nature. So there is no need to appeal to what God could do to establish the conclusions of $O E P, 1 . \mathrm{XXXI}$.

Scholars have generally not been concerned to highlight the distinctive features of Cavendish's argument for the three tenets of her anti-atomism discussed above. Indeed, Detlefsen (2007) claims that "[m]uch of Cavendish's matter theory can be easily explicated in terms of her acceptance or rejection of certain aspects of the philosophies of her contemporaries" (162) and explains her move from atomism to plenism in part via Cavendish's "assertion of the unending divisibility of matter" (pp. 162-163) without further explanation. ${ }^{42}$ Marshall (2014) regards Cavendish's argument as "commonly employed against atomism in the seventeenth century" (Sect. 2a). But given the causal conception of parts of nature and the associated conception of division as entailing composition, it seems that Cavendish's anti-atomism is rather distinctive. Perhaps we need to revisit the contention of Clucas (1994) that Cavendish is only rejecting a particular form of atomism, even if what she rejects is the only position we are now willing to call atomism. ${ }^{43}$ Indeed, the normative argument against even a plenist-vitalist atomism

\footnotetext{
42 To be fair, here is a passage, in addition to (i) the apparent recitation of the logico-mathematical argument at $O E P, 125$ on which Detlefsen (2006) relies and (ii) the rejection of Charleton's atomism at $P L, 4$.IX, 455 , that would seem to support Detlefsen's view as against mine.
}

...if atoms be bodies, I do not see how they can be indivisible: by reason, wheresoever is body, there are also parts; so that divisibility is an essential propriety of attribute of matter or body. (OEP, p. 263)

I claim that in context, where the whole discussion revolves around single parts, she is talking here about division in the sense that entails composition. On this reading, the conclusion is secured by the doctrine of complete blending, since where there is body, there is animate matter, and where there is animate matter, further movements are possible.

43 Cf. the comments on the fluidity of seventeenth-century notions of materialism at Duncan (2012), 404. 
is not an argument that it is impossible, but only that it seems fancifully inconsistent with the harmony of nature that we observe in the actual world. ${ }^{44}$

Our interest in Cavendish's anti-atomism arose in the course of trying to discern whether the horse-rider analogy breaks down when it comes to the arrangement in space of the three types of matter that she posits in her metaphysics. The foregoing discussion of Cavendish's remarks on division and her argument against atomism show that her commitment to infinite divisibility does not look like a promising ground for establishing that arbitrary subregions of parts of nature are effects of self-moving matter. But there is one more possibility for resolution, and I think it succeeds in ruling out the existence of unmixed spatial regions where all else has failed.

\section{Cavendish on place: spatial relations between types of matter}

Insofar as we can look to Cavendish to give us a direct answer about the spatial relations of the three degrees of matter, her theory of place holds the most promise. She identifies place with completely blended bodies.

...figure, place, and body are all one...(PL, 2.IX, p. 159)

...motion and body were not two several substances; but motion and matter made one self-moving body; and so was place, color, figure, etc. all one and the same with body. (OEP, p. 37)

Matter, Figure, or Place, is but one thing (GNP, 1.I, p. 2)

Given her general approach to Aristotelian accidents, this identification of place with body should be taken seriously. We have already seen that Cavendish regards motion as a kind of matter. Further, in the case of accidents other than motion, Cavendish consistently tells stories on which the accidents are reduced to or identified with the (self-)motion of matter. ${ }^{45}$ So in this section, I am going to consider three different ways of making sense of her identification of place with body. The third and final way, which I endorse, settles the issue of how far the horse and rider metaphor can itself be ridden. In particular, it will rule out the existence of unmixed spatial regions, resolving the question that has driven the preceding reevaluations of Cavendish's doctrine of complete blending and her anti-atomism.

What I take the identification of place and body to require is that we somehow make sense of thinking of each type of matter in a given part of nature as occupying the same space. One way to do this is by thinking of the different types of matter as aspects of a single substance. Another is to regard the different types of matter as systematically overlapping, interpenetrating one another throughout all of nature, and therefore also as interpenetrating one another throughout the place of any particular part of nature. A third is to reject the notion of spatial relations between types of matter altogether, and to say nothing about the spatial arrangement of particular types of matter, except by way of courtesy and derivatively on the basis of the place of the parts of nature

\footnotetext{
44 See Detlefsen (2006), Sect. 3.

45 For her view of color, see $O E P, 1 . \mathrm{XX}-\mathrm{XXI}$ and GNP, 12.XXIX, p. 214; for heat and smell, see $O E P$, 1.XXVII, p. 108; for heat and cold generally, see $O E P, 1 . X X V-X X I X$.
} 
that they compose. I have here presented these options in order of their increasing plausibility, in my view, as interpretations of Cavendish.

The aspect reading initially seems promising. But it cannot easily be made consistent with Cavendish's response to Q. 22 in $O E P, 1 . X X X V I I$. She allows there that rational matter "can quit some parts and join to others" (189). That is, she says that particular bits of rational matter need not always be associated with fixed particular bits of the other kinds of matter. But that means that rational matter cannot just be an aspect of a body, or else Cavendish's arguments against the transference of modes would apply. ${ }^{46}$

The overlapping/interpenetrating reading suffers less from the existence of directly contradictory passages, and more from Cavendish's turning away from opportunities to endorse it. To give the main example, there is some textual evidence for the view that Cavendish thinks that animate matter can penetrate inanimate matter. She mentions More's view that the immaterial can penetrate the material in $P L, 2$.XXI, treating his penetrability as a feature that rational matter actually has. She also says rational and sensitive matter are penetrating at $P L, 2$.XII and again says it about rational matter at $P L$, IV.29. She allows that light, which she takes to be material, may be penetrating at $P L, 1$ XXVI. However, Cavendish seems to differ from More and others on what it is for one material to penetrate another.

As for Penetration, I conceive it to be nothing else but division; as when some parts pierce and enter through other parts, as Duelers run each other through, or as water runs through a sieve. (PL, 2.XXIII, pp. 204-205) ${ }^{47}$

Cavendish does not seem to have yet another proprietary conception of division, on which her comments about the penetrative quality of rational matter actually amount to the claim that two kinds of body can occupy the same space. For Cavendish, as I showed in Sect. 3, to divide is to move in a particular way, to compose with other, previously distant parts. Penetration, as Cavendish here conceives it, is piercing, rather than what More holds that the immaterial can do to the material, and rather than what the overlapping reading of her identification of place with body would require.

The final reading, which I endorse, is that it makes no real sense to ask about the places of bits of individual types of matter. Rather, places are places of parts of nature (in the causal sense). So the place of, say, the rational matter that partially composes a given part of nature is, if anywhere, just the place of that part of nature itself. And likewise for its sensitive matter, and likewise for its inanimate matter. On this view, the horse-rider analogy is indeed misleading. Unmixed spatial regions are impossible, because Cavendish, in this instance like Descartes, has no notion of place apart from bodies, and bodies are always completely blended.

\footnotetext{
46 On the still-developing view of Eugene Marshall (p.c.), Cavendish's response to Q. 22 is just inconsistent with the rest of her metaphysics. But I think this conclusion can and should be avoided, and the aspect view should be rejected for endorsing it. An anonymous referee for Synthese suggests that the aspect view can be rescued by reading Cavendish as saying that, when rational matter "quits some parts and joins to others," it brings its (completely blended) sensitive and inanimate matter with it, as if Cavendish is here describing the regular process of division and composition. This reading is available, though it seems to me to require reading Cavendish as being deliberately unhelpful in going on, as she does, to discuss instances in which rational and sensitive matter move in different ways.

47 Thanks to Stewart Duncan for pointing this passage out to me.
} 
This interpretation actually justifies the crucial presupposition of O'Neill's reductio. The matter found in any region of space does constitute a particle of nature. That is not because you can choose arbitrary regions of three-dimensional Euclidean space and be certain that they will contain within their bounds at least one particle of nature. Rather, it is because choosing a place in order to consider the matter contained therein can be nothing other than choosing some completely blended part or parts of nature to examine. That is a simple consequence of Cavendish's identification of place with body. So the geometrical thinking behind the question that drove this paper up to the beginning of this section was itself an abuse of mathematics. No mathematical understanding of the doctrine of complete blending is needed.

\section{Conclusion}

This paper has tried to treat Cavendish as living up to her own billing: as "writ[ing] according to [her] own natural cogitations" (PPO, Chap. 209, 171). It has attributed to her significantly distinctive theories of parts of nature as effects of self-moving matter and of division as a kind of local motion that entails composition. It has also presented her as engaging in a kind of playing with terminology that was controversial in her own day and does not always get emphasized in the contemporary secondary literature. ${ }^{48}$ But it has also, I hope, led us to a deeper understanding of her doctrine of complete blending, revealed her original and hitherto little-appreciated argument against atomism, and presented a more consistent interpretation of a broader range of her texts. In the end, it has undermined its own guiding question as an illicit application of mathematical thought to an early modern metaphysical theory.

It is appropriate, both for this special issue and for a paper on Cavendish, that a geometric approach should prove to undermine itself in this way. After all, consider what Eric Schliesser would call Cavendish's anti-mathematicism, her reservations about the utility of mathematics for understanding nature. ${ }^{49}$ In her novel $T B W$, she represents mathematics as an unserious discipline at best.

The Empress... at last had a mind to divert herself after her serious discourses, and therefore she sent for the spider-men, which were her mathematicians, the licemen, which were her geometricians, and the magpie-, parrot- and jackdaw-men, which were her orators and logicians. ... [To the mathematicians, the Empress said,] that I can neither spare time from other affairs to busy myself in your profession; nor, if I could, do I think I should ever be able to understand your imaginary points, lines and figures, because they are non-beings.

Then came the lice-men... at which the Empress began to be displeased, and told them, that there was neither truth nor justice in their profession; and so dissolved their society. (TBW, pp. 45-46)

\footnotetext{
48 Compare Cavendish's crediting herself with misleading uses of Scholastic 'agent' and 'patient' terminology $(O E P, 18)$ with Walter Charleton's 1654 letter, in which he insinuates that Cavendish had more training than she let on $(C L P, 146)$.

49 See Schliesser $(2012,2014)$.
} 
While it is in general unclear to what extent Cavendish can be identified with the views of the Empress in $T B W$, there seems to be no reason to doubt that Cavendish is expressing her own views, through the Empress, on the relevance of mathematical investigations to the serious business of understanding nature. For my part I find them helpful in framing questions that can, as I hope to have shown above, lead to real understanding of philosophical views, even when anti-mathematicism wins the day. ${ }^{50}$

Acknowledgements Research for and writing of this paper were partly supported by FWO, the Flemish Research Foundation, through the Anti-Formalisering in de Wijsbegeerte research project, dossier number G061215N. Open access publication of this article was supported by funds provided through an agreement between Swedish universities, including Uppsala University, and the publisher.

Open Access This article is distributed under the terms of the Creative Commons Attribution 4.0 International License (http://creativecommons.org/licenses/by/4.0/), which permits unrestricted use, distribution, and reproduction in any medium, provided you give appropriate credit to the original author(s) and the source, provide a link to the Creative Commons license, and indicate if changes were made.

\section{References}

Bennett, J. (1996). Spinoza's metaphysics. In Garrett (1996), pp. 61-88.

Boyle, R. (1991). Selected philosophical papers of Robert Boyle. Indianapolis: Hackett Publishing Co.

Cavendish, M. (2001). Observations upon experimental philosophy. Cambridge: Cambridge University Press.

Cavendish, M. (2003). Political writings. Cambridge texts in the history of political thought. Cambridge: Cambridge University Press.

Clucas, S. (1994). The atomism of the Cavendish circle: A reappraisal. The Seventeenth Century, 9(2), 247-273.

Detlefsen, K. (2006). Atomism, monism, and causation in the natural philosophy of margaret cavendish, In Garber and Nadler (2006) (chap. 7, pp. 199-240).

Detlefsen, K. (2007). Reason and freedom: Margaret Cavendish on the order and disorder of nature. Archiv für Geschichte der Philosophie, 89(2), 157-191.

Detlefsen, K. (2009). Margaret Cavendish on the relation between god and world. Philosophy Compass, $4(3), 421-438$.

Duncan, S. (2012). Debating materialism: Cavendish, Hobbes, and more. History of Philosophy Quarterly, 29(4), 391-409.

Francks, R. (2003). Modern Philosophy: The seventeenth and eighteenth centuries. London: Routledge.

Garber, D., \& Nadler, S. (Eds.). (2006). Oxford Studies in Early Modern Philosophy, (Vol. 3). Oxford: Oxford University Press.

Garrett, D. (Ed.). (1996). The Cambridge Companion to Spinoza. Cambridge: Cambridge University Press.

Hatfield, G. C. (1979). Force (god) in descartes' physics. Studies in History and Philosophy of Science Part A, 10(2), 113-140.

James, S. (1999). The philosophical innovations of Margaret Cavendish. British Journal for the History of Philosophy, 7(2), 219-244.

\footnotetext{
${ }^{50} \mathrm{My}$ interest in the issues discussed in this paper arose as I was teaching a seminar on the continental rationalists and their female critics at Oberlin College. Thanks for copious discussion and inspiration are due to the students of that seminar, especially Nicholas Wilcox, and to the members of a Skype reading group on Observations upon Experimental Philosophy in which I participated in early 2015, especially to Becko Copenhaver, Wiebke Deimling, Liz Goodnick, John Komdat, Marcy Lascano, Eugene Marshall, Alison Peterman, and most crucially Lewis Powell, who organized the group and was kind enough to let me take part. Liz, Marcy, Stewart Duncan, Eric Schliesser, Tad Schmaltz, and the members of a writing workgroup at Ghent University, including Boris Demarest, Fons Dewulf, Iulia Mihai, Sylvia Pauw, and Pieter Present, read a draft of the paper and provided many helpful comments, as did two anonymous referees for Synthese. I am grateful to them all.
} 
Kargon, R. H. (1966). Atomism in England From Hariot to Newton. Oxford: Clarendon Press.

Lascano, M. (2015). Early Modern Women Philosophers: Cosmology and Human Nature. Unpublished manuscript.

Marshall, E. (2014). Margaret Cavendish. Internet Encyclopedia of Philosophy. http://www.iep.utm.edu/. O’Neill, E. (2001). Introduction. In Cavendish (2001), pp. 10-36.

O’Neill, E. (2013). Margaret Cavendish, stoic antecedent causes, and early modern occasional causes. Revue philosophique de la France et de l'étranger, 138(3), 311-326.

Schliesser, E. (2012). Adam Smith and anti-mathematics. SSRN eLibrary. http://papers.ssrn.com/sol3/ papers.cfm?abstract_id=2140828.

Schliesser, E. (2014). Spinoza and 'anti-mathematics'. HOPOS 2014.

Stevenson, J. (1996). The mechanist-vitalist soul of Margaret Cavendish. Studies in English Literature, 36, 527-543. 